\title{
Identification of caries risk in two-year-olds
}

\section{Authors}

Wigen $\mathrm{TI}^{1}$, Baumgartner $\mathrm{CS}^{1,2}$, Wang $\mathrm{NJ}^{1}$

${ }^{1}$ Department of Paediatric Dentistry and Behavioural Science

Institute of Clinical Dentistry

University of Oslo

Norway

${ }^{2}$ Dental Expertise Centre of Southern Norway, Arendal

Norway

\section{Running title}

Caries risk in two-year-olds

\section{Keywords}

Early childhood caries, caries increment, immigrants, preschool children, toothbrushing

\section{Corresponding author}

Tove I. Wigen

Department of Paediatric Dentistry and Behavioural Science

Institute of Clinical Dentistry

Box 1109, Blindern

0317 Oslo

Norway

Phone +4722852041

E-mail: wigen@odont.uio.no 


\section{Abstract}

Objective: The first aim was to describe presence of plaque, caries and oral health behaviours in two-year-old children. The second aim was to measure increments in caries experience from two to five years of age, and to study whether national background, visible plaque, caries and oral health behaviour at two years of age were associated with increments in caries experience. Methods: The study population consisted of 392 children, of whom 211 were monitored from two to five years of age. At age two years, parents completed a questionnaire about family background and oral health behaviour. The presence of plaque and caries at tooth level were obtained from dental records. Data were tested with Chi square statistics and Mann-Whitney-U test. Negative binomial regression analysis was conducted to explore the association between caries increment between two and five years of age and national background, visible plaque, caries and oral health behaviour at two years of age. Results: Caries was found in $4.6 \%$ of two-year-olds and $4.6 \%$ had visible plaque. More than half of these children (57.9\%) brushed twice daily, toothbrushing was introduced when the child was seven months or older in $61.0 \%$ of the children, and $15.6 \%$ consumed sugary snacks daily. Non-Western children more often had caries, visible plaque and unfavourable oral health behaviour than Western children $(\mathrm{p}<0.05)$. At age five years, $28.9 \%$ of the children had caries experience. Non-Western background, toothbrushing less than twice daily, not using fluoridated toothpaste, not using fluoride lozenges, consuming sugary drinks at night, consuming sugary snacks daily, presence of plaque and caries at two years of age were associated with caries increment between two and five years of age in bivariable analyses. The results from multivariable analysis showed that children who started toothbrushing late, children who brushed less than twice daily at two years of age and children of non-Western background had a higher probability of having caries increment from two to five years of age than other children. Conclusions: A small proportion of two-year-olds had caries, but these children had several decayed teeth. Substantial differences in oral health and oral health behaviour were found between western and non-western children. The preventive care delivered to the studied children failed to prevent caries increment, suggesting that it is worthwhile seeing caries risk children before at the age of two years. 


\section{Introduction}

The majority of children in Norway and in many other countries are not examined by dental personnel before the age of three years ${ }^{1}$. As a consequence, oral health data for children younger than three years is often not available. Caries prevalence in two-year-old children has been reported in some studies, showing that up to $10 \%$ of the children have developed caries by this age ${ }^{2-5}$. To attain the goal of a cavity-free future for children early identification of caries risk is essential ${ }^{6}$.

While some data are available on caries prevalence in two-year-olds, caries prevalence in five-year-old children is well documented. At five years of age, 20-40\% of children in Europe have been reported to have caries experience ${ }^{7-10}$. Caries development in preschool children has been associated with the family's socioeconomic situation and oral health behaviour ${ }^{11,12}$. Children with immigrant background and children of parents with low educational level have been shown to have higher caries prevalence than other children ${ }^{11,13,14}$. Toothbrushing frequency and sugar intake are associated with caries development in young children ${ }^{10,15-18}$. Some studies have reported that the presence of dental plaque and caries in early childhood was associated with caries increment during preschool age $9,19,20$.

Information to parents about caries prevention from birth given by primary care personnel is part of general health promotion in several countries ${ }^{1,21,22}$. In Norway, primary care personnel are required by national guidelines to give information about oral health to parents of infants and toddlers. Caries risk children should be identified early and referred to dental personnel ${ }^{23}$. Knowledge of risk factors for early caries development based on longitudinal studies may allow caries preventive strategies to be targeted towards risk families.

All children in Norway are invited to attend a first oral examination in the dental services at three years of age. Children receiving dental care at the student dental clinic at the University of Oslo were invited to their first dental visit at two years of age. The background for the study was to explore whether inviting two-year-olds for a first dental examination with individualized caries preventive advice would help prevent caries between two and five years of age. The first aim of this study was to describe the presence of dental plaque, caries experience and oral health behaviours in two-year-olds. The second aim was to measure increments in caries experience between two and five years of age, and to study whether 
national background, visible plaque accumulation, caries experience and oral health behaviour at two years of age were associated with increments in caries experience.

\section{Methods}

This study included children that according to home address had the student dental clinic at the University of Oslo as their regular dental clinic. All children were invited for an oral examination at two years of age between 2006 and 2010. The clinic is situated in an area of Oslo where preschool children have higher caries prevalence than average in Norway ${ }^{8,24}$. In total, 495 children were invited and 411 children (83.0\%) showed up for the oral examination. Nineteen children were excluded because of lack of data. The study population at two years of age consisted of 392 children, 198 boys and 194 girls. A higher proportion of children with Western background $(88.3 \%)$ came to the dental examination than children with non-Western background $(66.7 \%),(\mathrm{p}<0.05)$. Mean age at the examination at two years of age was 26.4 (SD 3.2) months.

Between two and five years of age, children were recalled at individualised intervals and given preventive care as needed. All children were called at least once a year. Of the children examined at two years of age, 211 (102 boys and 109 girls) were still living in the area and available for dental examination at five years of age. Mean age at this examination was 60.0 (SD 7.5) months. Among children who had moved from the area and were unavailable for dental examination at five years of age, the proportion of Western children was slightly higher $(48.9 \%$ versus $35.8 \%, \mathrm{p}=0.05$ ), and proportion of children with caries was lower $(1.7 \%$ versus $7.1 \%, \mathrm{p}<0.05)$ than among children still living in the area.

Oral examinations at two and five years of age included standard anamnestic information and dental examinations. The examinations were performed in a fully equipped dental clinic using mirror and probe after the teeth had been dried and was carried out by dental students or dental hygienist students. Dentists or dental hygienists verified all registrations. The data were registered in the children's dental records and extracted from the dental records by the examiners. Individualized caries preventive information and oral hygiene instruction were provided for all children and parents as part of the examination, including instructions on sugar consumption, use of fluoridated toothpaste and application of fluoride varnish if considered necessary by dental personnel.

Clinical examination at two years of age included registration of visible dental plaque accumulation and caries experience on all emerged teeth. Presence of plaque was recorded as 
visible and not visible. Clinical examination at five years of age included registration of caries. Caries experience was reported as decayed, filled or missing teeth (dmft). All teeth with caries both initial and manifest lesions, were categorized as decayed teeth. At five years of age, bitewing radiographs were taken when indicated in accordance with standard routines in the dental services (bitewings when visual inspection of approximal surfaces was impossible), and used in $41.2 \%$ of the children as an adjunct to the clinical caries registration. Caries increment was calculated as the difference in the number of teeth with caries experience at two and five years of age, and children were dichotomized as having or not having caries increment between two and five years of age.

At the examination at two years of age, parents completed a questionnaire which included anamnestic information; national background, oral health related behaviour and dietary habits. National background was recorded as parents' country of birth, and in the analyses categorised as both parents with Western background and one or both parents with non-Western background. Non-Western background included parents born in Asia, Africa, south- and central America and eastern Europe. In children who did not attend for dental examination the child's family name were used to indicate the child's national background.

Toothbrushing frequency was reported as twice daily, once daily, seldom and never, and in the analyses categorized as twice daily, once daily and less than daily. Child age when toothbrushing was started was categorized as younger than seven months and seven months and older. Use of fluoride lozenges was reported as daily and less than daily. The parents reported whether or not the child had access to sugar-containing drinks during the night, and access to sugar-containing snacks between meals was categorized as seldom/never, sometimes and daily.

Data analyses were conducted by use of SPSS for Windows (SPSS version 24, Inc Chicago, IL, USA). Results are presented as frequencies, mean and standard deviation (SD). Data were cross-tabulated and tested using Chi Square statistics, and differences between means were tested with Mann-Whitney-U test. Spearman's Rank correlation was used to explore collinearity between the independent variables before multivariable analysis was conducted In children monitored from 2 to 5 years of age, three variables had missing data in 3, 5 and 46 children, respectively. Missing data was replaced using multiple imputation to reduce loss of data in multivariable analysis. The association between caries increment between two and five years of age and the presence of plaque, caries and oral health 
behaviour at two years of age controlled for national background was explored using negative binomial regression analysis with caries increment between two and five years of age as the dependent variable. The Goodness of Fit was $>0.05$, and the Omnibus Test was $p<0.05$ showing that the model fitted the data well. The level of statistical significance was set at $5 \%$.

The study was performed as part of the quality assurance system required by law in the public dental services in Norway. Quality assurance and evaluation that are part of the health service do not require approval from ethical committees. All parents gave informed consent. Data analyses were conducted on anonymised data.

\section{Results}

In Table 1, clinical findings and reported oral health behaviours at two years of age are presented. Caries experience was registered in $4.6 \%$ of the children and $4.6 \%$ had visible plaque. Two-year-old children with a non-Western background more often had caries, visible plaque and unfavourable oral health behaviours compared with Western children ( $p>0.05)$.

Table 2 shows mean number of teeth with caries experience at two years of age according to national background, presence of plaque, caries experience and oral health behaviour at two years of age in the 211 children followed longitudinally. At two years of age, $6.6 \%$ of the children had caries experience, no children had filled or lost teeth because of caries. The mean number of teeth with caries experience was 0.3 (SD 1.4) teeth. Children with caries experience at two years of age (14 children) had on average 4.4 (SD 3.6) teeth with caries experience. Number of teeth with caries experience at two years of age was associated with having visible plaque, toothbrushing frequency, use of fluoride toothpaste, sugar drinks at night, sugar snacking and national background.

In Table 2, mean number of teeth with caries experience at five years of age and mean number of teeth with increment in caries experience between two and five years of age according to national background, presence of plaque, caries and oral health behaviour at two years of age are presented. At five years of age, $28.9 \%$ of the children had caries experience. Children having caries experience at two years of age developed statistically significantly more caries than children without caries experience at two years of age $(2.4$ vs. $0.7, p<0.05)$. Caries increment was associated with clinical findings at two years of age, oral health behaviour and national background. Children, who at two years of age did not use fluoridated toothpaste, brushed their teeth less than daily and children with non-Western background had 
the highest increase in number of teeth with caries experience between two and five years of age.

Negative binomial regression analysis exploring the relationship of caries increment between two and five years of age with national background, presence of plaque, caries and oral health behaviour and at two years of age was performed (Table 3). Age when introducing toothbrushing, toothbrushing frequency at the age of two years and national background were associated with increment in caries experience between two and five years of age. The other included variables (visible plaque, caries experience, use of fluoride toothpaste, use of fluoride lozenges, sugary drinks at night and sugar snacking at two years of age) were not statistically significantly associated with increment in caries experience.

\section{Discussion}

This longitudinal study aimed to explore oral health in two-year-old children and to measure increments in caries experience from two to five years of age. The findings showed that a small proportion of children had caries at two years of age. Age when introducing toothbrushing, toothbrushing frequency at two years of age and national background were related to increment in caries experience from two to five years of age.

The study was performed in an area which the children in the Norwegian context had high caries prevalence, and a high proportion of children were classified as needing extended and individualized caries preventive care before the age of three years. Seventeen per cent of children invited to participate did not attend for the dental examination, and it has been shown that non-attenders have caries experience more often than other children ${ }^{25}$. The proportion of two-year-old children with caries in the studied area may be higher than registered in this study because of non-attenders. Although some children did not participate, those who did were caries risk children, and the findings can be generalized to other areas with similar caries prevalence in young children.

Among children examined at two and five years of age, those with non-Western background and children who had caries at two years of age were overrepresented compared to children only examined at age two years. Thus a higher proportion of caries risk children was included in the analyses of increment in caries experience. Data were mainly used to study associations, and selection bias has been shown not to influence associations between variables ${ }^{26}$. This study was based partly on questionnaires, and limitations such as nonresponses, misconceptions and errors like answering in a social desirable way are present in 
all questionnaire studies ${ }^{27}$. The probability of recall and reporting error in the present study were considered limited as, most questions were related to daily routine of oral health habits in young children. Dental students and dental hygienist students performed the clinical dental examinations of children using the established caries diagnostic methods used at the University of Oslo. Experienced dentists or dental hygienists verified all registrations.

The findings showed that only a small proportion of the children had caries at two years of age, and most of these had non-Western background. Non-Western children also had a higher probability of developing caries during preschool age than Western children. It is well established that immigrant children have higher caries prevalence than native children ${ }^{28}$. This study also showed that non-Western children acquire carious lesions at a lower age than do Western children, and by the age of two years some children had developed several decayed teeth. Caries preventive care should ideally be provided before the children acquire carious lesions ${ }^{22}$. The reported differences in oral health behaviour between non-Western children and Western children may be due to cultural differences or that the parents did not understand the advice given, and indicate that non-Western parents need targeted oral health information. Oral health information is part of general health information given to all parents at well-baby clinics from the child's first weeks of life ${ }^{21}$. The findings showed that nonWestern parents less often follow the advice given than Western parents.

At two years of age, $20 \%$ of the children were being given sugar-containing drinks each night and $16 \%$ of the children received sugary snacks daily. These findings indicate a frequent sugar intake among the children. Sugar is a main cause of dental caries in young children ${ }^{29}$. Children with a high sugar intake at a young age often maintain the high sugar intake during childhood ${ }^{15}$, which in turn is associated with poor dental health and poor general health in later life ${ }^{30}$.

The findings from the longitudinal follow-up study showed substantial increment in caries experience, especially in children who had caries lesions at two years of age. The findings were in line with a study from Australia showing a marked increase in caries experience between 18 and 40 months of age ${ }^{31}$. All included children were given an individualized caries preventive program at two years of age. The findings showed that the preventive care delivered failed to prevent increment in caries experience in the studied children. The findings are in line with a newly published study from Ireland showing that 
biannual application of fluoride varnish did not keep children caries free during preschool age 32.

Increment in caries experience was associated with age when introducing toothbrushing and toothbrushing frequency at two years of age. Toothbrushing with fluoridated toothpaste is widely accepted as a caries preventive method in children ${ }^{33}$, and infrequent brushers have been shown to have higher caries prevalence in the primary dentition 17. We know that behaviours established at a young age are often maintained during childhood ${ }^{34}$; this includes oral health behaviours ${ }^{35}$.

Important finding from this study was that children who started toothbrushing late, children who did not brush their teeth daily by two years of age and children with nonWestern background were caries risk children and had a high probability of having increment in caries experience during preschool age. The results from this study confirm that some parents find it difficult to establish toothbrushing twice daily for their child and that nonWestern parents do not follow the oral health advice given. Such children should ideally be referred to dental personnel by primary care personnel earlier than at age two years for oral health advice so as to initiate favourable oral health behaviour and prevent the substantial increment in caries experience between two and five years of age. More research is necessary in children younger than two years of age to understand better parents' obstacles blocking favourable oral health behaviour in their children.

In conclusion, a minor proportion of two year olds had caries experience, and the children with caries had several decayed teeth. The preventive care delivered to the studied children failed to prevent caries increment. The findings indicate that it is worthwhile seeing caries risk children before at the age of two years to facilitate establishment of toothbrushing twice daily at an early age to prevent caries. 


\section{References}

1. Kuhnisch J, Ekstrand KR, Pretty I, Twetman S, Loveren C, Gizani S et al. Best clinical practice guidance for management of early caries lesions in children and young adults: an EAPD policy document. Eur Arch Paediatr Dent 2016; 17: 3-12.

2. Moimaz SA, Borges HC, Saliba O, Garbin CA, Saliba NA. Early childhood caries: Epidemiology, severity and sociobehavioural determinants. Oral health Prev Dent 2016; 14: $77-83$.

3. Wendt LK, Hallonsten AL, Koch G. Dental caries in one- and two-year-old children living in Sweden. Part I-a longitudinal study. Swed Dent J 1991; 15: 1-6.

4. Anderson M, Dahllof G, Twetman S, Jansson L, Bergenlid AC, Grindefjord M. Effectiveness of early preventive intervention with semiannual fluoride varnish application in toddlers living in high-risk areas: A stratified cluster-randomized controlled trial. Caries Res 2016; 50: 17-23.

5. Douglass JM, Tinanoff N, Tang JM, Altman DS. Dental caries patterns and oral health behaviors in Arizona infants and toddlers. Community Dent Oral Epidemiol 2001; 29: $14-22$.

6. Shashikiran ND. A step toward cavity-free future. J Indian Soc Pedod Prev Dent 2014; 32: $195-196$.

7. Monaghan N, Davies GM, Jones CM, Neville JS, Pitts NB. The caries experience of 5year-old children in Scotland, Wales and England in 2011-2012: reports of crosssectional surveys using BASCD criteria. Community Dent Health 2014; 31: 105-110.

8. Statistics Norway. Dental status by age 2016. Available at https://www.ssb.no/statistikkbanken/SelectTable/hovedtabellHjem.asp?KortNavnWeb=ta $\underline{\text { nnhelse } \& C M S S u b j e c t A r e a}=$ helse $\&$ StatVariant $=\&$ PLanguage $=1 \&$ checked $=$ true $\quad$ (Last accessed December $21^{\text {th }}$ 2017).

9. Leroy R, Bogaerts K, Martens L, Declerck D. Risk factors for caries incidence in a cohort of Flemish preschool children. Clin Oral Investig 2012; 16: 805-812.

10. Meurman PK, Pienihäkkinen K. Factors associated with caries increment: a longitudinal study from 18 months to 5 years of age. Caries Res 2010; 44: 519-524.

11. Harris R, Nicoll AD, Adair PM, Pine CM. Risk factors for dental caries in young children: a systematic review of the literature. Community Dent Health 2004; 21: 71-85. 
12. Leong PM, Gussy MG, Barrow SY, de Silva-Sanigorski A, Waters E. A systematic review of risk factors during first year of life for early childhood caries. Int J Paediatr Dent 2013; 23: 235-250.

13. Grindefjord M, Dahllöf G, Modéer T. Caries development in children from 2.5 to 3.5 years of age: a longitudinal study. Caries Res 1995; 29: 449-454.

14. Wigen TI, Espelid I, Skaare AB, Wang NJ. Family characteristics and caries experience in preschool children. A longitudinal study from pregnancy to 5 years of age. Community Dent Oral Epidemiol 2011; 39: 311-317.

15. Ruottinen S, Karjalainen S, Pienihäkkinen K, Lagström H, Niinikoski H, Salminen M, et al. Sucrose intake since infancy and dental health in 10-year-old children. Caries Res 2004; 38: 142-148.

16. Wigen TI, Wang NJ. Does early establishment of favorable oral health behavior influence caries prevalence at age 5 years? Acta Odontol Scand 2015; 73: 182-187.

17. Kumar S, Tadakamadla J, Johnson NW. Effect of toothbrushing frequency on incidence and increment of dental caries: A systematic review and meta-analysis. J Dent Res 2016; 95: $1230-36$.

18. Winter J, Glaser M, Heinzel-Gutenbrunner M, Pieper K. Association of caries increment in preschool children with nutritional and preventive variables. Clin Oral Investig 2015; 19: 1913-1919.

19. Wendt LK, Hallonsten AL, Koch G. Oral health in pre-school children living in Sweden. Part III-A longitudinal study. Risk analyses based on caries prevalence at 3 years of age and immigrant status. Swed Dent J 1999; 23: 17-25.

20. Andre Kramer AC, Skeie MS, Skaare AB, Espelid I, Ostberg AL. Caries increment in primary teeth from 3 to 6 years of age: a longitudinal study in Swedish children. Eur Arch Paediatr Dent 2014; 15: 167-173.

21. The Norwegian Directorate of Health. Tenner for livet. Helsefremmende og forebyggende arbeid. [Teeth for life. Health promotion and health prevention]. IS-2659. Oslo, 1999.

22. American Academy of Pediatric Dentistry. Guideline on infant oral health care. Pediatr Dent 2012; 34: 148-152.

23. Wigen TI, Wang NJ. Referral of young children to dental personnel by primary care nurses. Int J Dent Hyg 2017; 15: 249-255.

24. Skeie MS, Espelid I, Skaare AB, Gimmestad A. Caries patterns in an urban preschool population in Norway. Eur J Paediatr Dent 2005; 6: 16-22. 
25. Wigen TI, Skaret E, Wang NJ. Dental avoidance behaviour in parent and child as risk indicators for caries in 5-year-old children. Int J Paediatr Dent 2009; 19: 431-437.

26. Nilsen RM, Vollset SE, Gjessing HK, Skjaerven R, Melve KK, Schreuder P, et al. Selfselection and bias in a large prospective pregnancy cohort in Norway. Paediatr Perinat Epidemiol 2009; 23: 597-608.

27. Sjostrom O, Holst D, Lind SO. Validity of a questionnaire survey: the role of nonresponse and incorrect answers. Acta Odontol Scand 1999; 57: 242-246.

28. Congiu G, Campus G, Luglie PF. Early childhood caries (ECC) prevalence and background factors: a review. Oral Health Prev Dent 2014; 12: 71-76.

29. Sheiham A, James WP. Diet and Dental Caries: The Pivotal Role of Free Sugars Reemphasized. J Dent Res 2015; 94: 1341-1347.

30. Mishra MB, Mishra S. Sugar-Sweetened Beverages: General and Oral Health Hazards in Children and Adolescents. Int J Clin Pediatr Dent 2011; 4: 119-123.

31. Gussy M, Ashbolt R, Carpenter L, Virgo-Milton M, Calache H, Dashper S, et al. Natural history of dental caries in very young Australian children. Int J Paediatr Dent 2016; 26: 173-183.

32. Tickle M, O'Neill C, Donaldson M, Birch S, Noble S, Killough S, et al. A randomized controlled trial of caries prevention in dental practice. J Dent Res 2017; 96: 741-746.

33. Dos Santos AP, Nadanovsky P, de Oliveira BH. A systematic review and meta-analysis of the effects of fluoride toothpastes on the prevention of dental caries in the primary dentition of preschool children. Community Dent Oral Epidemiol 2013; 41: 1-12.

34. Ouellette J, Wood W. Habit and intention in everyday life:The multiple process by which past behavior predicts future behavior. Psychological Bulletin 1998; 124: 54-74.

35. Wigen TI, Wang NJ. Tooth brushing frequency and use of fluoride lozenges in children from 1.5 to 5 years of age. A longitudinal study. Community Dent Oral Epidemiol 2014; 42: 395-403. 
Table 1. Clinical findings, oral health behaviour and national background at two years of age. All children and children by national background $(n=392)$.

\begin{tabular}{|c|c|c|c|}
\hline \multirow[b]{2}{*}{ Two years of age } & $\begin{array}{l}\text { All children } \\
(n=392)\end{array}$ & $\begin{array}{l}\text { Western } \\
\text { children } \\
(n=311)\end{array}$ & $\begin{array}{l}\text { Non-Western } \\
\text { children } \\
(\mathrm{n}=81)\end{array}$ \\
\hline & $\%(n)$ & $\%(n)$ & $\%(n)$ \\
\hline \multicolumn{4}{|l|}{ Caries experience ${ }^{*}$} \\
\hline No & $95.4(375)$ & $99.0(309)$ & $81.5(66)$ \\
\hline Yes & $4.6(17)$ & $1.0(2)$ & $18.5(15)$ \\
\hline \multicolumn{4}{|l|}{ Visible plaque* } \\
\hline No & $95.4(374)$ & $98.1(305)$ & $85.2(69)$ \\
\hline Yes & $4.6(18)$ & $1.9(6)$ & $14.8(12)$ \\
\hline \multicolumn{4}{|c|}{ Age when started toothbrushing ${ }^{\dagger *}$} \\
\hline$<7$ months & $39.0(120)$ & $42.7(108)$ & $21.8(12)$ \\
\hline$\geq 7$ months & $48.0(188)$ & $57.3(145)$ & $78.2(43)$ \\
\hline \multicolumn{4}{|c|}{ Toothbrushing frequency* } \\
\hline Twice daily & $57.9(227)$ & $57.9(180)$ & $58.0(47)$ \\
\hline Once daily & $38.0(149)$ & $41.2(128)$ & $25.9(21)$ \\
\hline Less than daily & $4.1(16)$ & $1.0(3)$ & $16.0(13)$ \\
\hline \multicolumn{4}{|c|}{ Fluoride toothpaste ${ }^{*}$} \\
\hline Yes & $97.4(382)$ & $98.4(306)$ & $93.8(76)$ \\
\hline No & $2.6(10)$ & $1.6(5)$ & $6.2(5)$ \\
\hline \multicolumn{4}{|l|}{ Fluoride lozenges* } \\
\hline Daily & $46.2(181)$ & $50.5(154)$ & $33.3(27)$ \\
\hline Less than daily & $53.8(211)$ & $49.5(157)$ & $66.7(54)$ \\
\hline \multicolumn{4}{|c|}{ Sugar drinks at night ${ }^{\dagger *}$} \\
\hline No & $81.2(311)$ & $86.8(264)$ & $59.5(47)$ \\
\hline Yes & $18.8(72)$ & $13.2(40)$ & $40.5(32)$ \\
\hline \multicolumn{4}{|l|}{ Sugar snacking ${ }^{\dagger *}$} \\
\hline Seldom/never & $23.4(90)$ & $24.5(75)$ & $19.2(15)$ \\
\hline Sometimes & $60.9(234)$ & $62.7(192)$ & $53.8(42)$ \\
\hline Daily & $15.6(60)$ & $12.7(39)$ & $26.9(21)$ \\
\hline \multicolumn{4}{|l|}{ Background } \\
\hline Western (ref) & $79.3(311)$ & & \\
\hline Non-Western & $20.7 \quad(81)$ & ---- & ---- \\
\hline
\end{tabular}

tReduced because of internal drop-out.

$* \mathrm{p}<0.05$. 
Table 2. Teeth with caries experience (dmft) at the ages two and five years and change in caries experience ( $\Delta \mathrm{dmft}$ ) between two and five years of age according to clinical findings, oral health behaviour and national background at two years of age. Mean and standard deviations (SD). Children monitored from two to five years of age $(n=211)$.

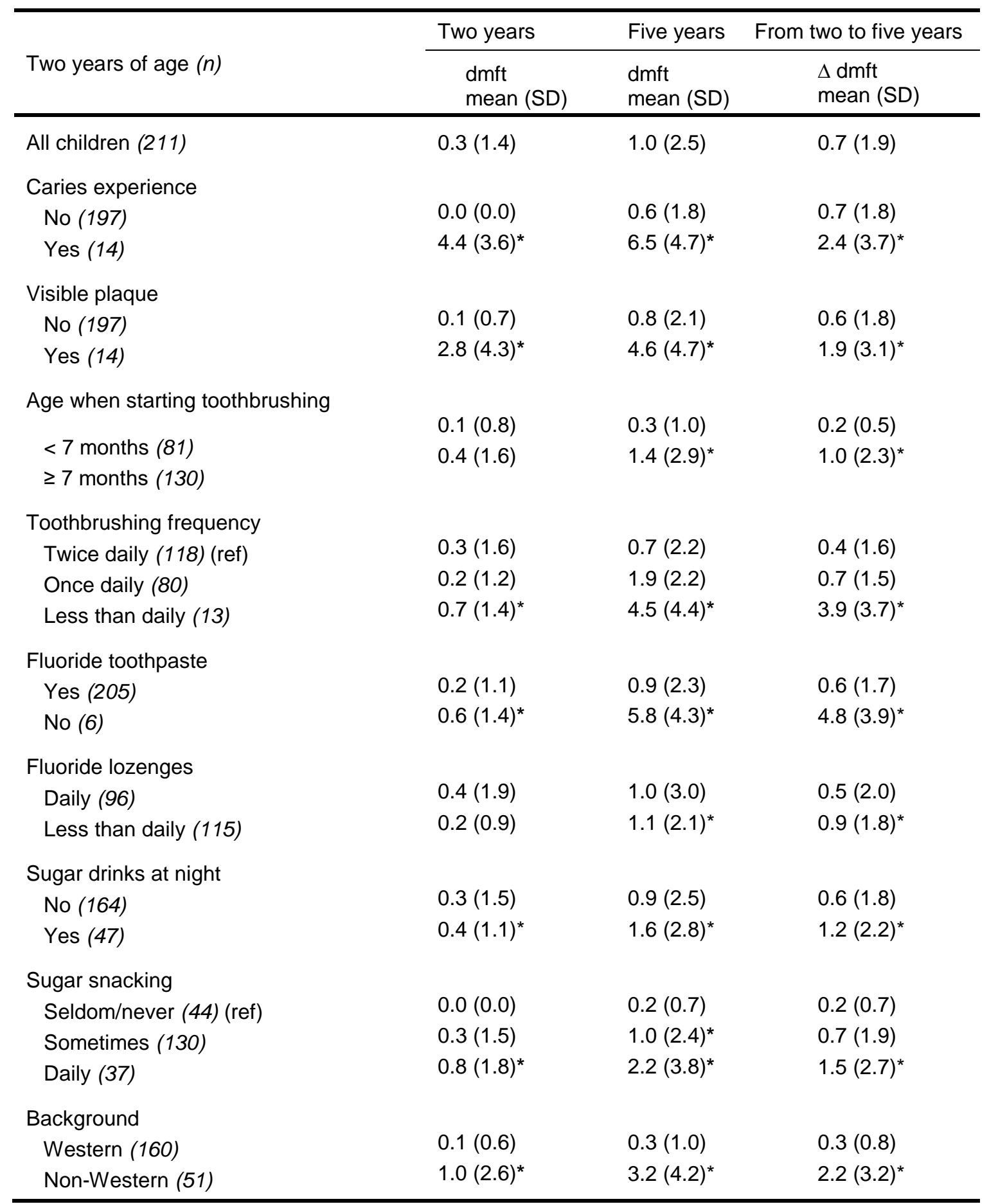

(ref) reference category.

$* \mathrm{p}<0.05$. 
Table 3. Results from negativ binomial regression analysis exploring the association between change in caries experience between two and five years of age and clinical findings, oral health behaviour and national background at two years of age $(n=211)$.

\begin{tabular}{|c|c|c|}
\hline Two years of age & OR & $95 \% \mathrm{Cl}$ \\
\hline \multicolumn{3}{|l|}{ Visible plaque } \\
\hline No & 1 & \\
\hline Yes & 0.3 & $0.1-1.1$ \\
\hline \multicolumn{3}{|l|}{ Caries experience } \\
\hline No & 1 & \\
\hline Yes & 1.2 & $0.5-2.9$ \\
\hline \multicolumn{3}{|l|}{$\begin{array}{l}\text { Age when starting } \\
\text { toothbrushing }\end{array}$} \\
\hline$<7$ months & 1 & \\
\hline$\geq 7$ months & 2.1 & $1.1-4.2$ \\
\hline \multicolumn{3}{|c|}{ Toothbrushing frequency } \\
\hline Twice daily & 1 & \\
\hline Once daily & 2.1 & $1.2-3.7$ \\
\hline Less than daily & 4.8 & $1.6-13.9$ \\
\hline \multicolumn{3}{|c|}{ Fluoride toothpaste } \\
\hline Yes & 1 & \\
\hline No & 1.5 & $0.3-6.9$ \\
\hline \multicolumn{3}{|l|}{ Fluoride lozenges } \\
\hline Daily & 1 & \\
\hline Less than daily & 1.5 & $0.9-2.7$ \\
\hline \multicolumn{3}{|c|}{ Sugar drinks at night } \\
\hline No & 1 & \\
\hline Yes & 1.2 & $0.7-2.0$ \\
\hline \multicolumn{3}{|l|}{ Sugar snacking } \\
\hline Seldom/never & 1 & \\
\hline Sometimes & 1.8 & $0.7-5.1$ \\
\hline Daily & 1.9 & $0.8-4.2$ \\
\hline \multicolumn{3}{|l|}{ Background } \\
\hline Western & 1 & \\
\hline Non-Western & 5.4 & $3.0-10.0$ \\
\hline
\end{tabular}

